\title{
Relationship between dorsal brainstem sleep sites and intracranial self-stimulation*
}

\author{
STEVEN J. ELLMAN, ROBERT F. ACKERMANN, JORGE FARBER \\ LINDA MATTIACE, and SOLOMON S. STEINER \\ City College of the City University of New York, New York, New York 10031
}

\begin{abstract}
Based upon our previous findings that a reciprocal relationship exists between intracranial self-stimulation (ICSS) and rapid eye movement (REM) sleep, we hypothesized that the ICSS neural network is a part of the REM sleep system and fires during REM sleep. A series of experiments was designed to test a corollary to this hypothesis, that some sites involved in triggering REM sleep are also ICSS sites. We explored five locations: the locus coeruleus (LC), the medial longitudinal fasciculus (MLF) (both posterior midbrain and pontine level), the dorsal longitudinal fasciculus (DLF) (midbrain), and the ventral raphe (pontine level). We obtained rate-intensity functions from each animal that displayed ICSS. High to very high (15,000 per hour) rates of ICSS were obtained at several dorsal brain sites. These sites included the LC, pontine aspects of the MLF, and posterior midbrain aspects of the MLF and DLF. ICSS from the LC is interpreted as evidence that noradrenergic ICSS sites are part of the REM sleep neural network.
\end{abstract}

Recently, Steiner and Ellman (1972) demonstrated a reciprocal relationship between intracranial self-stimulation (ICSS) and rapid eye movement (REM) sleep. They showed that depriving an organism of REM sleep raises response rates and lowers lateral hypothalamic ICSS thresholds, and that ICSS from the lateral hypothalamus (below convulsive levels) can substitute for REM sleep by lowering REM rebound. ${ }^{1}$ Spielman, Mattiace, Steiner, and Ellman (1973) have found that allowing rats hypothalamic ICSS reduces amounts of REM sleep in their "normal" sleep cycle. Based on these findings, we hypothesized that the ICSS neural network is part of the REM sleep system and fires during REM sleep. A corollary to this hypothesis is that some sites involved in triggering REM sleep are also ICSS sites. More specifically, the prediction was that the locus coeruleus (LC), a group of nuclei that are primarily noradrenergic (Dahlstrom \& Fuxe, 1964) supports ICSS. This hypothesis was based partly on Stein's (1964) contention that ICSS is produced in noradrenergic areas and on Jouvet's (1969) finding that the LC is involved in the triggering and maintaining of at least tonic aspects of REM sleep. In addition, Ungerstedt (1971) recently demonstrated that there are two fiber systems emanating from the LC that lead through the hypothalamus.

A second focus of the present study was to determine ICSS rates of response in both posterior midbrain and pontine (dorsal brainstem) sites. A previous study by Routtenberg and Malsbury (1969) indicated that "highest rates of self-stimulation (ICSS) are found only in the anterior midbrain." Their study was limited, however, in that ICSS response rates were elicited using only one electrical current level.

Two other studies (Margules, 1969; Crow, Spear, \&

*Supported in part by NIMH Grant 18908.
Arbuthnott, 1972) investigating dorsal brainstem sites suffered from a similar difficulty, in that rate-intensity functions were not reported. In one of these studies, Margules found that sites around the dorsal raphe nuclei supported ICSS. His conclusion was that a fiber tract, the dorsal longitudinal fasciculus (DLF), rather than raphe cell bodies, accounted for ICSS in this area. Our interpretation of his report led us to conclude that Margules was correct in asserting that the serotenergic cell bodies in this area did not support ICSS. However, his own figures seem to indicate that a more ventral fiber tract in this area, the medial longitudinal fasciculus (MLF), supports ICSS. We were particularly interested in this report, since the raphe nuclei in part initiate and maintain slow-wave or non-REM (NREM) sleep (Jouvet, 1969). We hypothesized that ICSS could be elicited from certain REM sleep nuclei, but not from nuclei that are involved in triggering and maintaining NREM sleep. We wished to demonstrate that both posterior midbrain and pontine aspects of the MLF support ICSS, and that the pontine aspects of the ventral raphe nuclei do not support ICSS. This would be further evidence for the assertion that in the dorsal raphe (DR) area, fiber tracts (the MLF or DLF) account for ICSS, rather than the serotenergic raphe cell bodies. This conclusion would seem justified if one could show that in divergent areas the same fiber tract (MLF) supported ICSS, while ICSS could be elicited from areas which contained raphe nuclei only when in the vicinity of this tract or another tract (DLF).

We explored five locations: the LC, the MLF (both posterior midbrain and pontine level), the DLF (midbrain), and the ventral raphe (pontine level). Our predictions were that ICSS would be obtained at the LC (a REM sleep area), both MLF sites, and the DLF, but not in the ventral raphe (a NREM area). In addition, we obtained data where the $\mathrm{S}$ was tested over a range of 


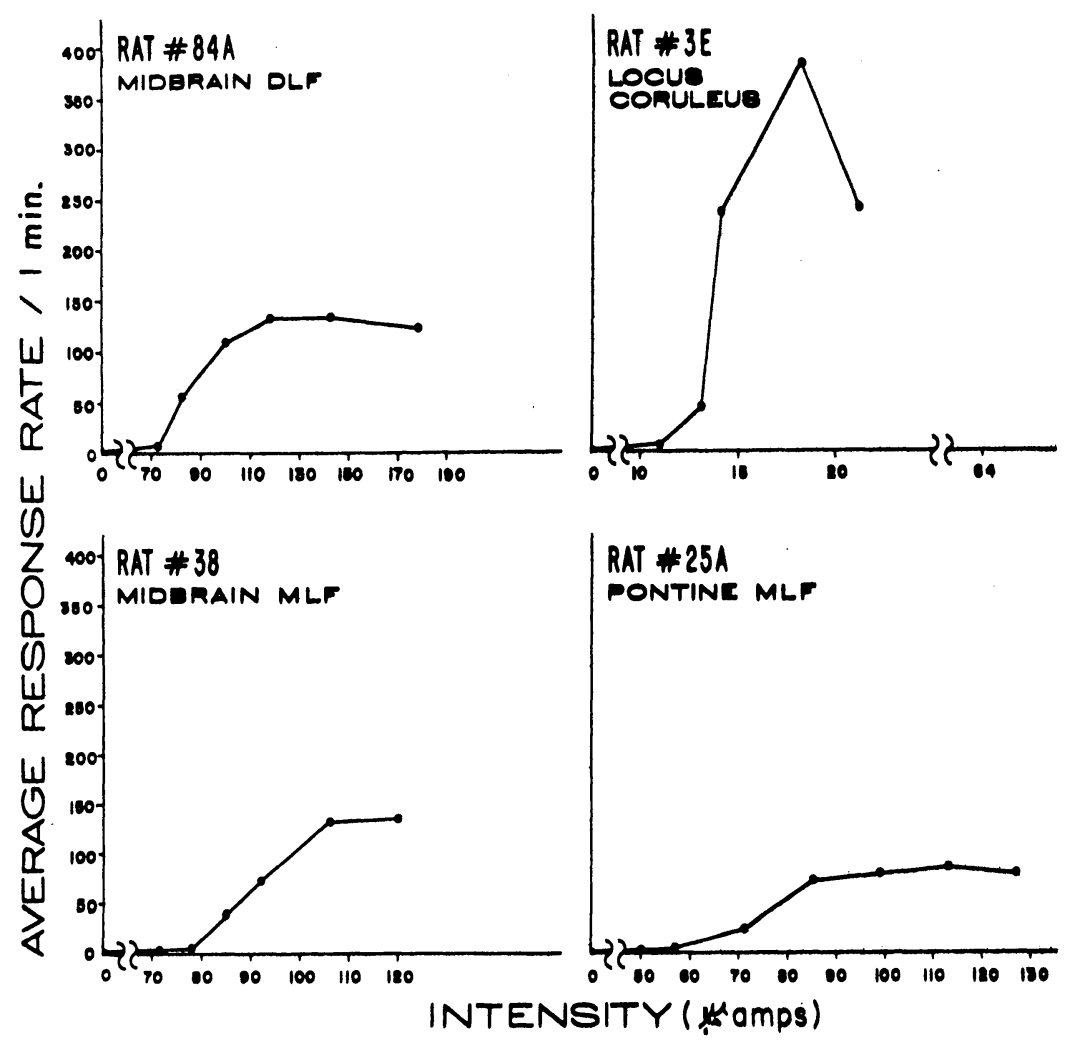

Fig. 1. Response rate per minute as a function of stimulus intensity in microamps for four representative Ss.

different intensities of stimulation, and rates of leverpressing were recorded for each intensity (rate-intensity function). In this situation, one can determine a threshold for electrical self-stimulation as well as a rate-intensity function. We obtained rate-intensity functions in order to more rigorously test Routtenberg and Malsbury's (1969) contention that highest rates of responding are obtained only at anterior midbrain placements.

\section{METHOD}

Ss were 37 male albino Sprague-Dawley rats, weighing between 250 and $300 \mathrm{~g}$ at the start of the experiment. Ss were anesthetized by intraperitoneal injection with Nembutal and chloral hydrate anesthetic. They were then stereotaxically implanted with a pair of bipolar electrodes aimed at the midbrain and pontine sites previously mentioned.

Stimulation consisted of biphasic sinusoidal $60-\mathrm{Hz}$ waves. Train duration was held constant at $0.25 \mathrm{sec}$, with the exception of one animal $(100 \mathrm{C})$, for which the duration was $0.5 \mathrm{sec}$. Current intensity was varied between trials according to the demands of the experiment and held essentially constant within trials by placing a megohm $1 \%$ resistor in series with the $\mathrm{S}$. Wave form and stimulus intensity were continuously monitored by observing the voltage drop across a megohm resistor in series with the $S$ on a cathode ray oscilloscope. Each $S$ was tested at at least six different intensities.

The apparatus consisted of a testing chamber constructed of Plexiglas and stainless steel. The chamber was $22 \mathrm{~cm}$ deep $x$ $20 \mathrm{~cm}$ wide $\times 20 \mathrm{~cm}$ high. A 3-cm-long $\times 3-\mathrm{cm}$-wide retractable metal lever was located $4 \mathrm{~cm}$ above the grid floor on one wall of the chamber. A force of $9 \mathrm{~g}$ was sufficient to depress the lever, and constituted a response. Electromechanical and solid sta ${ }^{+}$ switching circuitry in an adjacent room monitored Ss' behavior, recorded minute-by-minute response rates, and controlled contingencies of reinforcement.

Five to 10 days following surgery, Ss were tested at various stimulus intensities. We attempted daily to shape Ss to depress the lever for a brain stimulation reward by the method of successive approximation for a minimum of 15 days. A continuous reinforcement schedule was employed throughout the experiment. Those Ss who could not be shaped were killed, and the position of their electrodes verified histologically.

Ss who self-stimulated continued in testing. The threshold for self-stimulation was established by varying current intensities alternately in ascending and descending order. Rate-intensity functions were derived by allowing $S s$ to self-stimulate for $10 \mathrm{~min}$ at different intensity levels. Ss were run at the same time each day.

Following completion of the experiment, Ss were injected with an overdose of Nembutal and perfused with $0.9 \mathrm{~N}$ saline solution, followed by $10 \%$ Formalin solution. Frozen serial sections were then made and stained with luxol fast blue and cresyl violet. Electrode locus was determined by microscopic examination of the sections.

\section{RESULTS}

Sixteen out of the 37 Ss were shaped so that they would press a bar reliably for electrical stimulation. Of the Ss that demonstrated ICSS behavior, 5 were clearly in the LC (both dorsal and ventral aspects), 2 were in the MLF (pontine level), and 9 were in the DR area. Figure 1 presents a typical rate-intensity curve for an animal at each ICSS site.

We found sites in the pons that Routtenberg and Malsbury would classify either as very high (over 1,000 
Table 1

Response Rates at Different Sites

\begin{tabular}{|c|c|c|c|c|c|c|}
\hline $\begin{array}{c}\text { Animal } \\
\text { Number }\end{array}$ & Site & $\begin{array}{c}\text { Best Rate } \\
\text { (Responses } \\
\text { per Min) }\end{array}$ & $\begin{array}{c}\text { Intensity } \\
\text { for Best } \\
\text { Rates }(\mu \mathrm{A}) \\
\end{array}$ & $\begin{array}{c}\text { Low Rate } \\
\text { (Responses } \\
\text { per Min) }\end{array}$ & $\begin{array}{l}\text { Intensity } \\
\text { for Low } \\
\text { Rate }(\mu \mathrm{A}) \\
\end{array}$ & $\begin{array}{c}\text { Routtenberg } \\
\text { \& Malsbury } \\
\text { Rating } \\
\end{array}$ \\
\hline 36 & Midbrain MLF & 131.4 & 35 & 0 & 28 & Very High \\
\hline 38 & Midbrain MLF & 134.8 & 120 & 1.0 & 71 & Very High \\
\hline 50 & Midbrain MLF & 63.8 & 42 & 1.8 & 28 & High \\
\hline $25 \mathrm{~A}$ & Pons MLF & 83.5 & 113 & 6.1 & 57 & Very High \\
\hline $42 A$ & MLF Dorsolateral to Oculomotor Nuclei & 43.8 & 92 & 2.5 & 50 & High \\
\hline $65 \mathrm{~A}$ & Locus Coeruleus & 22.6 & 85 & 15.6 & 57 & Moderate \\
\hline $84 A$ & DLF & 143.8 & 148 & 6.6 & 127 & Very High \\
\hline $90 \mathrm{~A}$ & Edinger-Westphal, Oculomotor Nuclei & 135.6 & 99 & 63.6 & 78 & Very High \\
\hline $89 \mathrm{C}$ & Locus Coeruleus & 28.6 & 78 & 1.0 & 42 & Moderate \\
\hline $92 \mathrm{C}$ & Between the Dorsal Tegmental Nuclei (Pons MLF) & 68.0 & 156 & 9.0 & 57 & Very High \\
\hline $96 \mathrm{C}$ & DLF & 23.0 & 92 & 8.8 & 78 & Moderate \\
\hline $100 \mathrm{C}$ & DLF & 10.4 & 21 & 6.9 & 18 & Low \\
\hline $2 E$ & Midbrain MLF at Ventral Tegmental Nuclei & 47.2 & 127 & 0 & 57 & High \\
\hline $5 \mathrm{E}$ & Locus Coeruleus & 153.0 & 64 & No Data & - & Very High \\
\hline $17 \mathrm{E}$ & Locus Coeruleus & 24.6 & 99 & 9.8 & 71 & Moderate \\
\hline $26 \mathrm{E}$ & Midbrain MLF & 77.2 & 113 & 43.6 & 25 & Moderate \\
\hline $3 \mathrm{E}$ & Locus Coeruleus & 381.2 & 18 & 0.6 & 11 & Very High \\
\hline
\end{tabular}

Note-All animals were run at $0.25 \mathrm{sec}, 60 \mathrm{~Hz}$ sine except $100 \mathrm{C}$, which was run at 0.5-sec duration.

responses per $15 \mathrm{~min}$ ) or high (501-1,000 responses) rates. They, however, stated that electrodes in the dorsal brainstem are neutral $(0-50)$ or yield low $(51-200)$ to high $(501-1,000)$ rates, but not very high rates $(>1,000)$. Moreover, two of our LC animals' response rates compare with the very highest response rates that have been reported in the ICSS literature, to our knowledge $(15,000$ to 20,000 per hour $)$.

Table 1 presents data for all 16 Ss that include an animal's highest and lowest rate of response (per 15-min period), the site of the electrode, and a classification using Routtenberg and Malsbury's categories. They used five response categories: very high (over 1,000 responses), high (501-1,000), moderate (201-500), low (50-201), neutral (0-50), based on a 15-min time period. As can be seen in Table 1, all of our animals' highest response rates are at least at the moderate level, using this type of classification system.

Our demonstration that placements in the DR area yield ICSS is confirmation of Margules's study (1969). In our opinion, Margules's placements are too ventral to be in the DLF, and we conclude that his findings, as well as some of ours, are the result of stimulating the MLF. We do, however, have three animals whose electrode tracks impinge on the DLF, which supports his contention that the DLF is an ICSS site. The ventral raphe did not yield ICSS, despite prolonged testing. Other non-ICSS sites that we explored were: the reticular formation at the pontine level, superior colliculus, IV ventricle, and various sites in the cerebellum.

A behavioral observation that is striking to us is that dorsal brainstem animals' behavior during ICSS seems discriminably different from animals' behavior during hypothalamic ICSS. Hypothalamic animals seem quite excited and exhibit sniffing, licking, and various exploratory behaviors. In contrast, dorsal brainstem animals seem curiously unemotional despite their high response rates. Similarly, Crow, Spear, and Arbuthnott noted differences in locomotor activity between ventral tegmental and LC placements. In a recent study (1973), we demonstrated that dorsal brainstem ICSS is similar to hypothalamic ICSS in at least one respect: both types of ICSS sites support escape behavior.

\section{DISCUSSION}

At this point, we have demonstrated that there are ICSS sites in the pons, and we conclude that the LC is an ICSS site. Crow, Spear, and Arbuthnott (1972) have also recently reported that the LC is an ICSS site. ${ }^{2}$ Jouvet has previously demonstrated that the LC triggers and maintains REM sleep. Steiner and Ellman (1972) and Spielman, Mattiace, Steiner, and Ellman (1973) have shown that there is a reciprocal relationship between hypothalamic ICSS and REM sleep. Since we have now shown that the LC is an ICSS site, this result, coupled with our previous results, lends support to the conclusion that the noradrenergic ICSS system is part of and is fired during REM sleep. In addition, we conclude that the MLF, whether at the pontine or posterior midbrain level, yields self-stimulation behavior. Both our results and Margules's results support this contention, and we have offered additional evidence that the raphe cell bodies do not support ICSS. At this point, we may state that only those sleep nuclei involved in triggering REM sleep yield ICSS; to state the converse, NREM sleep areas do not support ICSS.

We feel that discrepancies between our results and those of Routtenberg and Malsbury are partly due to differences in experimental procedure. They tested Ss at one, relatively low, intensity ( 25 microA), while we tested Ss at a wide variety of intensities. Some of our 
animals whose electrode placements were in the pons had thresholds that were initially higher than the single intensity that Routtenberg and Malsbury used in their experiment. It is also probable that their electrodes were not in the appropriate sites to obtain ICSS in the LC. In our experience, highest rates of ICSS from the pons are obtained from the dorsal aspects of the LC. It is difficult from the microfiche of their histology to tell whether Routtenberg and Malsbury had an electrode in or near this site; they do not mention this site in their text. At any rate, we should comment that positive areas in the pons seem to be quite small and discrete, and, contrary to their report, very high response rates can be elicited from posterior midbrain and pontine sites.

We view our study as support for the contention that at least noradrenergic ICSS sites are part of the REM neural network. Ungerstedt (1971) recently demonstrated that there are two fiber systems emanating from the LC that lead through the hypothalamus. We propose that this tract forms a LC-hypothalamic ICSS network that fires during REM sleep. We also maintain that some of the behaviors resulting from REM deprivation, such as hyperphagia, hypersexuality (Dement, 1960; Morden, Mitchell, \& Dement, 1967), and lowering of hypothalamic ICSS thresholds (Steiner \& Ellman, 1972), are mediated by this neural network.

\section{REFERENCES}

Crow, T. J., Spear, P. J., \& Arbuthnott, G. W. Intracranial self-stimulation with electrodes in the region of the locus coeruleus. Brain Research, 1972, 36, 275-287.

Dahlstrom, A., \& Fuxe, K. Evidence for the existence of monoamines in the central nervous system. I. Demonstration of monoamines in the cell bodies of brain stem neurons. Acta Physiologica Scandinavica, 1964, 62 (Suppl. 232), 1-55.

Dement, W. C. The effect of dream deprivation. Science, 1960, 131, 1705-1707.

Jouvet, M. Biogenic amines and the states of sleep. Science, $1969,163,32-41$.
Margules, D. L. Noradrenergic rather than serotonergic basis of reward in the dorsal tegmentum. Journal of Comparative \& Physiological Psychology, 1969, 67, 32-35.

Morden, B., Mitchell, G., \& Dement, W. Selective REM sleep deprivation and compensation phenomena in the rat. Brain Research, 1967, 5, 339-349.

Routtenberg, A., \& Malsbury, C. Brainstem pathways of reward. Journal of Comparative \& Physiological Psychology, 1969, 68, 22-30.

Spielman, A., Mattiace, L., Steiner; S., \& Ellman, S. The effects of varying amounts of electrical self-stimulation on the "normal" sleep cycle of the rat. Sleep Research, 1973, in press. (Abstract)

Stein, L. Self-stimulation of the brain and the central stimulant action of amphetamine. Federation Proceedings, 1964, 23, 836-850.

Steiner, S. S., Bodnar, R. J., Ackermann, R. F., \& Ellman, S. J. Escape from "rewarding" brain stimulation of dorsal brainstem and hypothalamus. Physiology \& Behavior, 1973, 11 , in press.

Steiner, S. S., \& Ellman, S. J. Relation between REM sleep and intracranial self-stimulation. Science, 1972, 177, 1122-1124.

Ungerstedt, U. Stereotaxic mapping of monoamine pathways of the rat brain. Acta Physiologica Scandinavica, 1971, (Suppl. 367), 1-48.

\section{NOTES}

1. If a mammalian organism is deprived of REM sleep, usually in a subsequent sleep period, the REM-deprived organism will have elevated amounts of REM sleep to make up for the lost REM sleep. The elevated amounts of REM subsequent to REM deprivation is called REM rebound.

2. Our studies apparently were in progress at about the same time. Our first published report occurred in 1970 (NIMH Grant 18908), and we reported the findings at EPA in the spring of 1971 before the Crow et al report appeared. Our experience, while overlapping to some extent, differed with respect to theoretical orientation, neuroanatomical areas explored, and their use of one intensity of stimulation compared to our use of rate-intensity techniques.

(Received for publication July 31, 1973; accepted October 4, 1973.) 